\title{
Awareness and Knowledge of Hiv Transmission and Prevention Among Military Personnel In Abuja, Nigeria
}

Olajide Ayodele Adekunle

Chapman University https://orcid.org/0000-0003-2627-300X

David A. Adeyemi ( $\nabla$ david.crownsworth@gmail.com )

University of Ibadan https://orcid.org/0000-0003-0337-0130

\section{Research}

Keywords: Knowledge, HIV transmission, HIV prevention and military personnel

Posted Date: May 25th, 2021

DOI: https://doi.org/10.21203/rs.3.rs-551093/v1

License: (c) (1) This work is licensed under a Creative Commons Attribution 4.0 International License.

Read Full License 


\section{Abstract \\ Background}

The personnel of the Nigerian military indulge in high-risk sexual behaviors and hence, they pose as a potential core transmission group of HIV to the larger population. Despite the initiation and implementation of various strategies of improving adequate knowledge of HIV transmission and prevention, there is still high proportion of military personnel without appropriate knowledge of preventing HIV transmission. The aim of this study is to assess level of knowledge of HIV prevention and transmission and identify factors influencing transmission of HIV among military personnel in Nigeria.

\section{Methods}

A cross-sectional study design, using a semi-structured questionnaire was used to collect data on respondents' socio-demographic characteristics, utilization of male condom. Data was analyzed using descriptive statistics, Chi-square tests and logistic regression at $p<0.05$.

\section{Results}

While $98.5 \%$ of respondent have ever heard of HIV, $80.3 \%$ claimed to have seen or heard information about HIV, with media (85.9\%) been the major source of this information. Out of the 391 respondents, 174 (44.5\%) and 217 (55.5\%) military personnel had inadequate and adequate knowledge of HIV transmission respectively while $80.8 \%$ and $19.2 \%$ of these respondents had inadequate and adequate knowledge of HIV prevention, respectively.

\section{Conclusions}

While there was no significant difference in the proportion of those military men that had adequate and inadequate knowledge of HIV transmission, there was a clear and significant difference in the proportion of military men with adequate and inadequate prevention knowledge. Age, education, marital status, and service arm are predictive factors that could influence knowledge of HIV transmission and prevention.

\section{Introduction}

Human Immunodeficiency Virus (HIV) continues to become a generalized epidemic affecting all population groups and sparing no geographical area in NIgeria. HIV/AIDS has negatively impacted every sector of the economy and threatened the national development gains of the past decades. Despite the implementation of various programmes in the last two decades, HIV/AIDS remains a challenge and the burden of disease continues to increase in Nigeria. In Nigeria, HIV prevalence among the Nigerian military personnel (NMP) has been reported to be higher than that of the general population. Several reasons 
have been given for this, among which is the working condition of soldiers ${ }^{1}$. It is commonly the case that military personnel are generally young, sexually active people imbibed with feelings of invincibility and a greater inclination toward high-risk behaviour compared to the public. By virtue of the nature of their work, which involves a large degree of mobility and long periods of staying away from their families, they engage in high-risk sexual behaviors that expose them to STDs and HIV/AIDS ${ }^{2}$.

Military populations have formed one of the largest and most mobile sectors of society. The personnel of the Nigerian military indulge in high-risk sexual behaviors with low condom use, which put them at high risk of contracting STDs, including HIV. The implications of this are two-fold. Firstly, the risk of contracting HIV may threaten the preparedness of the military to carry out its functions, which is to maintain the country's territorial security and secure its borders from violation on land, sea, or air. Secondly, since military personnel live amongst the civilian population, they can serve as a potential core transmission group of these infections to the larger population ${ }^{2}$. Therefore, to enforce or improve HIV prevention strategies in Nigeria, it is imperative to encourage, public sensitization, information, education, and communication; condom promotion, and behaviour change campaign among the military men.

Nigerian government with the support of non-governmental organizations consistently conduct public education campaigns about HIV/AIDS transmission and prevention. Interventions currently being used to limit HIV transmission include promoting abstinence before marriage; encouraging faithfulness to one partner, through a combination of mass media campaigns and counselling; and various HIV education programs ${ }^{2}$. Some of these efforts are likely to bear fruit if they are sustained and spread across the entire country. Primary prevention interventions targeted at vulnerable populations is one of the most realistic strategies for controlling further spread of HIV in the country ${ }^{3}$. The most effective interventions are those that focus on population groups with the highest transmission rates. Prevention through behaviour change, condom promotion, and STI treatment is thought to be the most cost-effective approach ${ }^{4}$. The Armed Forces Programmes on AIDS (AFPAC), which came into being in 1987, has been at the forefront of the national efforts against HIV/AIDS in the military. AFPAC is a comprehensive programme focusing on both prevention and treatment for uniformed personnel, their family members, and military schools. The main areas of AFPAC programme include reduction in the transmission of HIV/AIDS and other STIs through preventive education, promotion of healthy behaviour and risk reduction strategies; voluntary counselling and testing; treatment of infected persons; and provision of home-based care and support for people living with HIV/AIDS. The major risk reduction activities of the programme include the development and distribution of information, education, and communication (IEC) materials, behaviour change communication activities, condom promotion, training of counsellors and establishment of counselling centres in health facilities training and use of peer education approach.

In Nigeria as elsewhere, personnel in the military are an important target for primary prevention interventions because they have a high risk of exposure to sexually transmitted infections (STI) including $\mathrm{HIV}^{3}$. In peacetime, STI infection rates among armed forces are generally 2 to 5 times higher than in comparable civilian populations and are even greater in times of conflict. AIDS is now the leading cause 
of death in military and police forces in some African countries, accounting for more than half of inservice mortality ${ }^{3}$. The burden of this disease can however be reduced if focus can be the strategy of improving change in sexual behaviour among the military men. Sexual behavior of adolescents is important not only because of the possible reproductive outcomes but also because risky sexual behavior, such as unprotected sex and low and inconsistent condom usage during sexual intercourse have been associated with increased HIV infection ${ }^{5}$.

Despite the initiation and implementation of various strategies of improving adequate knowledge of HIV transmission and prevention, there is still high proportion of military personnel without adequate knowledge of preventing transmission of HIV. Therefore, this study will add to the body of knowledge through the identification of predictors of poor level of knowledge and perception of HIV transmission and prevention among military personnel, who are among the most-at-risk groups for HIV infection. It will also provide pointers to areas where interventions could be focused, particularly to improve HIV prevention among military personnel. Provision of mitigating solutions to the problem can contribute to personnel education and awareness, programming strategies by the military to improve health and wellbeing of their officers and men. Understanding the soldiers' sexual behavior may also assist in obtaining insight into the best approach to prevent HIV among the military. The aim of this study is to assess level of knowledge of HIV prevention and transmission among military personnel in Abuja, Nigeria. This study also identifies factors that might be influencing programs to improve knowledge and perception of HIV prevention and transmission among the military personnel in Nigeria.

\section{Methodology}

This study was carried out in Abuja, the capital city of Nigeria, which situates in the center of the country (spanning $713 \mathrm{~km}^{2}$ on coordinates $9^{\circ} 4^{\prime} 0^{\prime \prime}$ North and $7^{\circ} 29^{\prime} 0^{\prime \prime}$ East of the equator), within the Federal Capital Territory (FCT). This population comprises mainly civil servants, businessmen and women, traders, security operatives, that is, military and para-military forces. The Nigerian Armed Forces comprises the Nigerian Army (NA), the Nigerian Air Force (NAF) and the Nigerian Navy (NN). Nigerian Armed Forces has its headquarters at Abuja and various units in each state of the federation. The forces are composed predominantly of males.

This is a cross-sectional survey of uniformed personnel in the Nigerian Defense Headquarters, Abuja. The inclusion criteria consist of uniformed men in all three arms of the force, working and residing in Abuja, FCT. They are deployed to combat war locally and internationally anytime the need arises. Sample size(n) was 384 and adjusted sample size was 427 respondents. Using the stratified probability sampling technique, participants were recruited based on arm of service with percentage distribution of 60:20:20 (Army, Navy and Air Force respectively). Proportional allocation was applied according to the percentage distribution set at 60:20:20 (Army, Navy, Air Force respectively). Therefore, the sample size was 257 respondents for Nigerian Army while 86 respondents were for Navy and Air Force, respectively. 
The tool for data collection was a structured self-administered questionnaire. A modified version of an Armed Forces Programme on AIDS Control (AFPAC) HIV/AIDS prevention indicator survey questionnaire was used. This instrument, divided into 3 sections, was designed to obtain information on sociodemographics (sex, age, ethnic background, education level as highest level of education attainment, experience in the military; arm of service, rank, length of service, gender and number of sexual partners, knowledge of HIV prevention, and perception of risk of HIV transmission. To confirm the reliability of the instrument, analysis of pre-test data was done using Cronbach $\llbracket s$ Alpha correlation coefficient of the Statistical Package for Social Sciences (SPSS). Alpha (Cronbach $\ \mathrm{~s}$ ) is a model of internal consistency, based on the average inter-item correlation (http://www.spss.com). This was done to ascertain the psychometric properties of the instrument. According to this approach, the result showed a correlation coefficient greater than 0.05 and this is said to be reliable. The dependent variables in this study were HIV transmission and HIV prevention knowledge among military personnel at the Defense Headquarters, Abuja, while the independent variables include age, sex, relationship status, education, ethnicity, religion, military experience. HIV transmission and prevention knowledge scores were calculated according to the fact that military personnel can answer yes or no to questions used to define the dependent variables. The scores were divided into two categories, inadequate and adequate knowledge.

Data entry, cleaning and analyses were carried out using SPSS. 16.0 statistical software (SPSS Inc. USA). Descriptive statistics such as graphs, charts, mean, and standard deviation were used to summarize data. A bivariate analytic tool: Chi-square test was used to establish relationship between sexual behaviour, knowledge of HIV transmission and prevention and socio-demographic variables. Logistic regression was used to determine strength of association between the dependent and independent variables. In the analysis carried out, statistical significance was considered at $P \leq 0.05$.

\section{Results}

\section{Socio-demographic characteristics of the respondents}

The ages of the respondents ranged from 18-55 years with a mean of 34 years \pm 1.89 (median $=36$ ). The total number of respondents was 397 (that is, a response rate of $93 \%$ ), out of which $13.4 \%$ were female. Majority (40.3\%) were aged 35-44 years, while most of the respondents $(69.3 \%)$ were married. Two hundred and ninety-one (73.3\%) respondents are Christians while $26.7 \%$ are Muslims. Two hundred and thirty-three (58.7\%) had tertiary education while 154 (38.8\% had secondary education, 7 (1.8\%) primary and $3(0.8 \%)$ had no formal education. Majority of the respondents, $151(38.0 \%)$ were from other ethnic backgrounds, while Yoruba were 111 (28.0\%), Igbos were 59 (14.9\%) and Hausas were 76 (19.1\%).

\section{Table 1: Awareness of HIV}




\begin{tabular}{|ll|}
\hline Variables & Frequency (\%) \\
\hline Ever heard of HIV & $6(1.5)$ \\
Yes & $391(98.5)$ \\
Total & $397(100.0)$ \\
\hline Do you believe it exist? & \\
No & $6(1.5)$ \\
Yes & $377(96.4)$ \\
Unsure & $5(1.3)$ \\
Don't know. & $3(0.8)$ \\
Total & $391(100.0)$ \\
\hline Heard or seen any information about AIDS virus. & \\
No & $77(19.7)$ \\
Yes & $314(80.3)$ \\
Total & $391(100.0)$ \\
\hline Major source of information & \\
Media & $336(85.9)$ \\
Family/Friends & $5(1.3)$ \\
Co-worker & $11(2.3)$ \\
Sex-partner & $2(0.5)$ \\
Health worker & $3(1.8 .1)$ \\
Others & $391(100.0)$ \\
\hline
\end{tabular}

Table 1 shows that $98.5 \%$ of the respondents have heard of HIV and $96.4 \%$ believed it exists. Three hundred and seventeen respondents have heard or seen information about the HIV virus, with the media $(85.9 \%)$ been the major source of this information while AFPAC/EPIC initiative accounting for $1.8 \%$ as source of information.

Table 2: Knowledge scores for HIV transmission 


\begin{tabular}{|llll|}
\hline Variables & No (\%) & Yes (\%) & Total (\%) \\
\hline Correct & & & \\
\hline From pregnant women to unborn child & $134(34.3)$ & $257(65.7)$ & $391(100.0)$ \\
\hline Sex with an infected person & $14(3.6)$ & $377(96.4)$ & $391(100.0)$ \\
\hline Blood transfusion & $34(8.7)$ & $357(91.3)$ & $391(100.0)$ \\
\hline Contaminated or re-used needles & $62(15.9)$ & $329(84.1)$ & $391(100.0)$ \\
\hline Incorrect & & & \\
\hline Using a toilet & $372(95.1)$ & $19(4.9)$ & $391(100.0)$ \\
\hline Mosquito bites & $364(93.1)$ & $27(6.9)$ & $391(100.0)$ \\
\hline Sharing eating utensils & $113(35.3)$ & $278(71.1)$ & $391(100.0)$ \\
\hline Shaking hands/non-intimate contact & $365(93.4)$ & $26(6.6)$ & $391(100.0)$ \\
\hline Circumcision & $138(35.3)$ & $253(64.7)$ & $391(100.0)$ \\
\hline Others & $273(69.8)$ & $118(30.2)$ & $391(100.0)$ \\
\hline
\end{tabular}

Out of the 391 respondents that indicated that they had knowledge about HIV transmission, 174 (44.5\%) military personnel had inadequate knowledge with 0-7 scores, while 217 (55.5\%) personnel had adequate knowledge of HIV transmission with scores of 8-10. The knowledge score was computed by summing the overall score over 10. Participants that affirmatively answered to all correct methods and negatively to all incorrect methods of HIV transmission had a perfect score of 10 . Those with affirmed 3 correct and negated 6 incorrect methods scored 9, while those with affirmed 2 and negated 6 incorrect methods of transmission scored 8. These scores were classified as 'adequate knowledge'. Respondents that have a summation of affirmed responses to between 0 and 2 correct methods and any number of negative responses (between 0 and 6), were all classified as 'inadequate knowledge'.

\section{HIV modes of prevention}

Of the 391 military personnel that responded to the possibility of preventing HIV infection, 372 (95.1\%) believed that something can be done to prevent HIV while 19 (4.9\%) believed that nothing can be done to prevent the disease.

Table 3: Knowledge scores for HIV prevention 


\begin{tabular}{|llll|}
\hline Variables & No (\%) & Yes (\%) & Total (\%) \\
\hline Correct & & & \\
\hline Abstinence & $96(24.6)$ & $295(75.4)$ & $391(100.0)$ \\
\hline Using condoms & $38(9.7)$ & $353(90.7)$ & $391(100.0)$ \\
\hline Stick to one partner & $38(9.7)$ & $353(90.7)$ & $391(100.0)$ \\
\hline No sex with prostitutes & $74(18.9)$ & $317(81.1)$ & $391(100.0)$ \\
\hline No sex with casual partners & $89(22.8)$ & $302(77.2)$ & $391(100.0)$ \\
\hline Avoid blood transfusion & $122(31.2)$ & $269(68.8)$ & $391(100.0)$ \\
\hline Avoid sharing shaving blades & $48(12.3)$ & $343(87.7)$ & $391(100.0)$ \\
\hline Avoid sharing nail cutter & $74(18.9)$ & $317(81.1)$ & $391(100.0)$ \\
\hline Avoid injection with contaminated needles & $54(13.8)$ & $337(86.2)$ & $391(100.0)$ \\
\hline Incorrect & & & \\
\hline Prevention by prayer & $237(60.6)$ & $154(39.4)$ & $391(100.0)$ \\
\hline Avoid kissing & $298(76.2)$ & $93(23.8)$ & $391(100.0)$ \\
\hline Avoid mosquito bites & $367(93.9)$ & $24(6.1)$ & $391(100.0)$ \\
\hline Avoid herbal preparations & $382(97.7)$ & $9(2.3)$ & $391(100.0)$ \\
\hline Avoid antibiotics, injections, and other medications & $374(95.7)$ & $17(4.3)$ & $391(100.0)$ \\
\hline Seek protection from traditional healer & $385(98.5)$ & $6(1.5)$ & $391(100.0)$ \\
\hline Others & $378(96.7)$ & $13(3.3)$ & $391(100.0)$ \\
\hline
\end{tabular}

Out of the 391 personnel that had knowledge about HIV prevention, $80.8 \%$ of these respondents had inadequate knowledge, while only $19.2 \%$ had adequate knowledge of HIV prevention. The knowledge score was computed by summing the overall score over 16 . Participants that affirmatively answered to all correct modes and negatively to all incorrect modes of HIV prevention had a perfect score of 16 , those with affirmed responses between 4-7 correct and negated 6 incorrect methods scored 9, while those with affirmed 2 and negated 6 incorrect methods of transmission scored 8; these scores were classified as 'adequate knowledge'. Respondents that have a summation of affirmed responses to between 0 and 2 correct methods and any number of negative responses (between 0 and 6 ), were all classified as 'inadequate knowledge'. 


\begin{tabular}{|c|c|c|c|c|}
\hline Variables & Inadequate knowledge & Adequate knowledge & $X^{2}$ values & $P$ values \\
\hline \multicolumn{5}{|l|}{ Gender } \\
\hline Male & $275(81.4)$ & $63(18.6)$ & \multirow{3}{*}{0.47} & \multirow{3}{*}{0.491} \\
\hline Female & $41(77.4)$ & $12(22.6)$ & & \\
\hline Total & $316(80.8)$ & 75 (19.2) & & \\
\hline \multicolumn{5}{|l|}{ Age group } \\
\hline $18-24$ & $2(66.7)$ & $1(33.3)$ & \multirow{5}{*}{2.31} & \multirow{5}{*}{0.510} \\
\hline $25-34$ & $6(85.7)$ & $1(14.3)$ & & \\
\hline $35-44$ & $117(77.5)$ & $34(22.5)$ & & \\
\hline $45-55$ & $191(83.0)$ & $39(17.0)$ & & \\
\hline Total & $316(80.8)$ & $75(19.2)$ & & \\
\hline \multicolumn{5}{|l|}{ Education } \\
\hline None & $2(66.7)$ & $1(33.3)$ & \multirow{5}{*}{2.31} & \multirow{5}{*}{0.510} \\
\hline Primary & $6(85.7)$ & $1(14.3)$ & & \\
\hline Secondary & $117(77.5)$ & $34(22.5)$ & & \\
\hline Tertiary & $191(83.0)$ & $39(17.0)$ & & \\
\hline Total & $316(80.8)$ & 75 (19.2) & & \\
\hline \multicolumn{5}{|c|}{ Marital Status } \\
\hline No & 79 (83.2) & $16(16.8)$ & \multirow{3}{*}{0.44} & \multirow{3}{*}{0.506} \\
\hline Yes & $237(80.1)$ & 59 (19.9) & & \\
\hline Total & $316(80.8)$ & 75 (19.2) & & \\
\hline \multicolumn{5}{|c|}{ Service arm } \\
\hline Army & $182(77.4)$ & $53(22.6)$ & \multirow{4}{*}{4.49} & \multirow{4}{*}{0.106} \\
\hline Navy & $68(87.2)$ & $10(12.8)$ & & \\
\hline Air Force & $66(84.6)$ & $12(15.4)$ & & \\
\hline Total & $316(80.8)$ & 75 (19.2) & & \\
\hline \multicolumn{5}{|l|}{ Rank } \\
\hline Officers & $20(80.0)$ & $5(20.0)$ & \multirow{3}{*}{0.012} & \multirow{3}{*}{0.914} \\
\hline Others & $296(80.9)$ & 70 (19.1) & & \\
\hline Total & $316(80.8)$ & 75 (19.2) & & \\
\hline
\end{tabular}




\begin{tabular}{|lllll|}
\hline Ethnicity & & & & \\
Yoruba & $85(79.4)$ & $22(20.6)$ & 7.91 & 0.048* \\
Igbo & $49(83.1)$ & $10(16.9)$ & & \\
Hausa & $53(70.7)$ & $22(29.3)$ & & \\
Others & $129(86.0)$ & $75(19.2)$ & & \\
Total & $316(80.8)$ & & & \\
Religion & & $49(17.1)$ & & \\
Christianity & $237(82.9)$ & $26(24.8)$ & & \\
Islam & $79(75.2)$ & $75(19.2)$ & & \\
Total & $316(80.8)$ & & &
\end{tabular}

\section{*Significant at $p<0.05$}

Only $18.6 \%$ of the male personnel and $22.6 \%$ of the female personnel had adequate knowledge of HIV prevention. Lower proportions of the personnel in all age groups and levels of education had adequate knowledge of HIV prevention, though age group 18-24 years and no formal education experienced the highest proportion of adequate knowledge of HIV prevention (33.3\%) compared to others. Sixteen (16.8\%) of 95 unmarried personnel and 59 (19.9\%) of 296 married personnel had adequate knowledge of HIV prevention. About $23 \%$ of Army personnel had adequate knowledge, while about $13 \%$ and $15 \%$ of Navy and Air Force personnel respectively had adequate knowledge of HIV prevention. This shows that higher proportion of Army personnel had adequate knowledge of HIV prevention compared to other service arms. Twenty per cent of Officers and $19 \%$ of other ranks had adequate knowledge of HIV prevention. About $20.6 \%, 16.9 \%, 29.3 \%$ and $14.0 \%$ of the personnel in Yoruba, Igbo, Hausa, and other ethnic groups had adequate knowledge of HIV prevention, respectively. There was however a statistical association between knowledge of HIV prevention and ethnicity at $p<0.05\left(X^{2}=7.91, p=0.048\right)$. Finally, about $17.1 \%$ of respondents that are Christians and $24.8 \%$ of Muslims had adequate knowledge of HIV prevention. In all, there were no statistical association at $p<0.05$ between knowledge of HIV prevention and sociodemographic characteristics, except ethnicity which was significant at $p<0.05$.

\section{Table 5: Logistic regression}




\begin{tabular}{|c|c|c|c|c|}
\hline \multicolumn{5}{|c|}{ Logistic regression of Ever heard or seen any information on HIV/AIDS } \\
\hline Variables & Beta & $p$-values & OR & $95 \% \mathrm{Cl}$ \\
\hline \multicolumn{5}{|c|}{ Service arm (ref-Army) } \\
\hline Navy & -0.653 & $0.030 *$ & 0.520 & $0.288-0.939$ \\
\hline Air Force & 0.180 & 0.615 & 1.197 & $0.594-2.410$ \\
\hline \multicolumn{5}{|c|}{ Age group (ref-18-24) } \\
\hline $25-34$ & 0.764 & 0.058 & 2.147 & $0.975-4.731$ \\
\hline $35-44$ & 1.563 & $0.000 *$ & 4.772 & $2.082-10.936$ \\
\hline $45-55$ & 1.792 & $0.001^{*}$ & 6.000 & $2.109-17.066$ \\
\hline \multicolumn{5}{|c|}{ Marital Status (ref-Single) } \\
\hline Married & 0.670 & $0.015^{*}$ & 1.954 & $1.139-3.351$ \\
\hline \multicolumn{5}{|c|}{ Logistic regression of Knowledge of HIV prevention } \\
\hline \multicolumn{5}{|c|}{ Age group (ref-45-55) } \\
\hline $18-24$ & -0.507 & 0.261 & 0.602 & $0.248-1.460$ \\
\hline $25-34$ & -0.953 & $0.004^{*}$ & 0.386 & $0.203-0.731$ \\
\hline $35-44$ & -0.669 & $0.037^{*}$ & 0.512 & $0.273-0.961$ \\
\hline \multicolumn{5}{|c|}{ Service arm (ref-Army) } \\
\hline Navy & -0.966 & $0.000 *$ & 0.381 & $0.224-0.646$ \\
\hline Air Force & 0.195 & 0.475 & 1.215 & $0.712-2.075$ \\
\hline \multicolumn{5}{|c|}{ Rank (ref- Officers) } \\
\hline Other ranks & -0.922 & 0.055 & 0.398 & $0.155-1.019$ \\
\hline \multicolumn{5}{|c|}{ Education (ref- None) } \\
\hline Primary & -1.609 & 0.278 & 0.200 & $0.011-3.661$ \\
\hline Secondary & -0.600 & 0.627 & 0.549 & $0.049-6.180$ \\
\hline Tertiary & -0.251 & 0.838 & 0.778 & $0.070-8.703$ \\
\hline
\end{tabular}

\section{*Significant at $p<0.05$}

The respondents in the age group of 25-34 years and 35-44 years were respectively about 0.4 times and 0.5 times more likely to have good knowledge of HIV prevention than those in the reference ( $45-55$ years age) group. These observations were significant with $p=0.004$ and $p=0.037$ respectively for the age groups. However, military personnel in the 18-24 years age group were 0.6 times more likely to have good 
knowledge of HIV prevention than those in 45-55 years age group but this is not statistically significant. Army personnel were about 2.6 times more likely to have good knowledge of HIV prevention than those in the Navy, and this was statistically significant at $p<0.05$. Respondents in the Air Force were 1.2 times more likely to have good knowledge of HIV prevention than those in the Army. This observation was however not statistically significant with $p=0.475$.

\section{Change in behaviour to prevent HIV/AIDS infection}

About $96.5 \%$ of the respondents reported to have changed behaviour to prevent contracting HIV/AIDS. However, $16.0 \%$ and $19.9 \%$ of the respondents that changed behaviour to prevent infection with HIV by not having sex and by stopping all sexual acts, respectively. About $74.5 \%$ of these respondents started using condom, $82.0 \%$ restricted to one sex partner and $61.5 \%$ reduced number of sex partners. Almost $77 \%$ of the respondents advised partners to be faithful, $51.2 \%$ said 'no' to homosexual contacts, $75.1 \%$ ensured sterilized needles and $71.1 \%$ avoided sharing razors or clippers.

Among those that reported to have 'no' or 'small' risk of getting HIV, $61.8 \%$ reported that they abstain from sex, while $87.7 \%, 81.8 \%, 74.7 \%$ and $78.9 \%$ reported to avoid multiple sex partners, sex with prostitutes, sex with homosexuals and sex with casual partners, respectively. Two hundred and thirty five respondents $(82.5 \%)$ reported to use condom during sexual acts.

\section{Discussion}

\section{Socio-demographic characteristics}

The mean age of respondents in this study was $35.89 \mathrm{yrs}$. This value is above the mean age in similar studies among Karachi fishermen ${ }^{6}$, among military recruits in Zaria, Nigeria ${ }^{7}$ and among the military in Sierra Leon ${ }^{8}$. The age rage represents a period of high sexual activities in the general population thus it will usually remain an area of public health interest to HIV/AIDS issues. More than two third of the respondents are married. There were more married respondents in previous studies $\left(82.2 \%{ }^{8}\right.$ and $\left.70.5 \%{ }^{9}\right)$. Despite the itinerary nature of military job, these men have homes and spouses they return to after their assignments. Their risky sexual lifestyles while they are away might put their wives at equal risk of the HIV disease since couples are traditionally not expected to use sexual safeguard except for contraceptives purposes.

\section{Military personnel knowledge of HIV transmission and prevention}

It is well known that the future trend of the HIV pandemic to a large extent depends on the level of HIV/AIDS awareness and knowledge in both civilian and military populations. Furthermore, an appreciable level of knowledge of the different modes of transmission of HIV and how to prevent it, are important prerequisites for behavior change. For this reason, most national programmes have put a great deal of effort into information, education, and communication (IEC) campaigns. Over a half of the respondents had adequate knowledge of HIV transmission, while a significant proportion of respondents

Page $12 / 18$ 
(80.8\%) have inadequate knowledge of HIV prevention. In addition, some still have misconceptions and partial knowledge of the modes of transmission of HIV and practice invalid preventive measures. HIV/AIDS health education campaigns need to focus on these issues. This finding is dissimilar to the findings among the military, in which only $40.0 \%$ of the respondents had good knowledge of HIV transmission and prevention, while $25.0 \%$ had poor knowledge of HIV/AIDS ${ }^{10}$. These proportions are quite different from the findings in which majority of the military recruits (93.6\%) indicated that HIV can be transmitted through infected blood transfusion and $86.7 \%$ who knew that HIV could be transmitted through unprotected heterosexual/bisexual ${ }^{7}$. Similarly, study showed that $71.0 \%$ among Nigerian naval personnel and $92.8 \%$ of army personnel had good knowledge of HIV transmission ${ }^{3}$. The proportion of military personnel with adequate knowledge of HIV transmission and prevention in this study is not appreciable enough and it might be largely due to their constant postings out of base that might have made them miss the opportunity of benefitting from organized HIV awareness and counselling programmes. The aftermath of not having adequate information about HIV transmission and prevention among the military personnel might results into practice of risky unprotected sexual escapades, thereby increasing the burden of the disease in the community. Therefore, to achieve the 2030 sustainability Developmental Goals, there is a need for a targeted intervention of a thorough and sustained campaign on improving knowledge of HIV/AIDS among military personnel.

Even though the prevalence of HIV knowledge and means of prevention are not encouraging, three quarters of all respondents reported use of condom during sexual intercourse. This is like the high prevalence of condom use (60\%) reported among sexually active tertiary students in Ethiopia ${ }^{11}$, while a South African study revealed $44.5 \%$ of women respondents inconsistently used condom in their last sexual practice ${ }^{12}$. However, the statistic of this study shows that those having sex without protection have heightened risk of HIV transmission and create a potential trap of infection to unprotected future partners with negative HIV status.

Chi square analysis carried to determine the possible factors responsible for the lower proportion of military personnel having adequate knowledge of HIV transmission and prevention shows that majority of personnel in the independent variables such as gender, age-groups, education, marital status, service arm, religion, and ethnicity, have inadequate knowledge of HIV transmission and prevention. However, there was not statistical significance in the analysis except for ethnicity. While higher proportion of yoruba and hausa respondents had good knowledge of HIV prevention compared to those in the Igbo ethnic group. However, we cannot possibly conclude that ethnic belief is a contributing factor to having poor knowledge among these military men because of non-uniformity in the sampling method. This result might be due to bias. However, there should be interventions to improve knowledge of HIV transmission and prevention especially at the level of education, ethnic groups, and arms of service. These results were supported by a study, which shows that about $24.1 \%$ of the married military female had poor knowledge of HIV/AIDS ${ }^{13}$. Lower proportion of Igbo respondents $(12.5 \%)$ compared to $26.3 \%$ of hausa and $35.0 \%$ of Yoruba had poor knowledge. 
Military personnel in the Navy were about 0.5 times more likely to have heard or seen any information on HIV/AIDS than those in the Army (reference category). This is significant at $p=0.030$ and $95 \%$ confidence interval $(\mathrm{Cl})$ of $0.288-0.939$. Air-Force personnel were about 1.2 times more likely to have heard or seen any information on HIV/AIDS than the personnel in the Army, though this was however, not statistically significance at $p<0.05$ and $95 \% \mathrm{Cl}$. In terms of age group, respondents in the age groups 35-44 years and 45-55 years were respectively about 4.8 times and 6.0 times more likely to have heard or seen any information on HIV/AIDS than those in the age group 18-24 years which is the reference category. These observations were statistically significant at $p<0.05$ and $95 \% \mathrm{Cl}$. There is also a statistical significance between marital status of respondents and if they ever heard or saw any information on HIV/AIDS. The married respondents were about 2.0 times more likely to have heard or seen any information on HIV/AIDS than the single respondents $(p=0.015,95 \% \mathrm{Cl}$ of $1.954-3.351)$.

Independent variables such as age group, marital status and educational level could influence the awareness and knowledge of transmission and prevention of HIV among military men. Though, they are not statistically significant. However, interventions could be focused on certain group of people in these independent variables. For example, a study pointed out that single female military personnel were more likely to have poor knowledge about HIV transmission and prevention compared to the married respondents ${ }^{13}$. It was also found out that those respondents below 30 years of age had poor knowledge compared to the older respondents.

\section{Conclusion}

The study was able to find a comparatively low level of HIV transmission and prevention among military personnel in Nigeria. While there was no significant difference in the proportion of those military men that had adequate and inadequate knowledge of HIV transmission, there was a clear and significant difference in the proportion of military men with adequate and inadequate prevention knowledge. The study also found out that independent variables such as age, education, marital status, and service arm are predictive factors that could influence knowledge of HIV transmission and prevention. Planning and implementing strategic interventions would go a long way in improving awareness and knowledge of HIV. These interventions should emphasize on promoting education and HIV awareness training among all service arm and all age groups, while considering the psychosocial factors and social environments in the Nigerian military.

\section{Recommendations}

Based on the findings of this study, certain targeted interventions should be instituted among certain groups of military personnel in Nigeria. To preserve the lives of military personnel and secure the overall peace and security of the country, knowledge based promotional activities and awareness should be encourage among socio-economic and cultural groups in the military. Sexual education and counseling should also be encouraged among all age groups especially the younger officers, marital status, and military ranks. 


\section{Limitations}

While the study was able to determine proportion of military personnel with good knowledge of HIV/AIDS transmission and prevention and possibly some socio-economic or demographic factors that might influence the poor knowledge among the respondents, the study could not establish causal relation between the dependent and independent variables. However, more studies should be carried out to establish indicators of HIV transmission and prevention knowledge.

\section{Abbreviations}

HIV

Human Immunodeficiency Virus

AIDS

Acquired Immune Deficiency Syndrome

SDG

Sustainable Development Goals

NMP

Nigeria Military Personnel

STD

Sexually Transmitted Diseases

AFPAC

Armed Forces Programmes on AIDS

WHO

World Health Organization

IEC

Information, Education, and Communication

\section{Declarations}

Ethics approval and consent to participate: Written approval was collected and preserved from Ethics Committee of College of Medicine, University of Ibadan, Oyo State and Ministry of Defense Health Research Ethics Committee, by the authors. Informed consent was also requested from individual respondents that participated in the research study.

Consent for publication: Please, kindly find the attached consent form.

Availability of data and materials: All dataset and materials (Questionnaire) used for the research study and analysis are available with the corresponding author and shall be released on request.

Competing Interest: All the authors declare no competing interest. 
Funding: The authors have no relevant affiliations or financial involvement with any organization or entity with a financial interest in or financial conflict with the subject matter or materials discussed in the manuscript apart from those disclosed.

Authors' contributions: This study was carried out in collaboration between all authors. Author DAA designed the study and managed the literature searches while author OAA wrote the first draft of the manuscript, performed the analyses of the study, and made necessary corrections on the manuscript. All authors read and approved the final manuscript.

Acknowledgement: We hereby acknowledge the support of College of Medicine, University of Ibadan, Oyo State and Ministry of Defense Health Research Ethics Committee while seeking ethical approval for the study. We also acknowledge the sincere response from the members of the armed forces of Nigeria.

\section{References}

1. Holmes Jr., Ogungbade GO, Ward DD, Garrison O, Peters RJ, Kalichman SC, Lahai-Momohe J, Essien EJ. Potential markers of female condom use among inner city African American Women. AIDS Care, 2008 Apr; 20(4): 470-477.

2. Adebajo SB, Mafeni J, Moreland S, Murray N. Knowledge, Attitudes, and Sexual Behaviour Among the Nigerian Military Concerning HIV/AIDS and STDs. Armed Forces Programme on AIDS Control (AFPAC) Technical Report, POLICY Project, September 2002.

3. Nwokoji UA and Ajuwon AJ. Knowledge of AIDS and HIV risk-related sexual behavior among Nigerian Naval personnel. BMC Public Health 2004, 4: 24.

4. Nasidi A and Harry TO. The epidemiology of HIV/AIDS in Nigeria. AIDS in Nigeria: A nation on the threshold. Cambridge (Massachusetts): Harvard Center for Population and Development Studies, 2006 pp.17-36.

5. Olowo E. Bamikole, Magbagbeola D. Dairo and Olajide A. Adekunle. Pattern of Condom Usage among Male and Female Youths in Nigeria from 1999 to 2008. International STD Research \& Reviews 2019:7(4): 1-12.

6. Zafar M, Nisar N, Kadir M, Fatmi Z, Ahmed Z, and Shafique K. Knowledge, attitude, and practices regarding HIV/AIDS among adult fishermen in coastal areas of Karachi. BMC Public Health. 2014; 14:437.

7. Igboanusi CJ, Dahiru T and Joshua IA. HIV/AIDS Knowledge and Attitude among Military Recruits at Depot Nigeria Army, Zaria, Nigeria. American Journal of Public Health Research. 2015, 3(1), 8-14.

8. Larsen MM, Casey SE, Sartie MT, Musa T, Tommy J, and Saldinger M. Changes in HIV/AIDS/STI knowledge, attitudes and practices among commercial sex workers and military forces in Port Loko, Sierra Leone. Disasters, 2004, 28(3): 239-254.

9. Hussein J, Newlands D, D'Ambruoso L, Thaver I, Talukder R, Besana G. Identifying practices and ideas to improve the implementation of maternal mortality reduction programmes: findings from five 
South Asian countries. BJOG 2010; 117: 304-313.

10. Ekong E. Sexual History, Behaviour and Practice of HIV/AIDS Prevention among Recruits of Depot Nigeria Army, Zaria-Nigeria. American Journal of Public Health Research. 2015; 3(2):51-55.

11. Mavhandu-Mudzusi AH, and Asgedom TT. The prevalence of risky sexual behaviours amongst undergraduate students in Jigjiga University, Ethiopia. Health SA Gesondheid 2016; 21:179-186.

12. Shai NJ, Jewkes R, Levin J, Dunkle K, and Nduna M. Factors associated with consistent condom use among rural young women in South Africa. AIDS Care. 2010; 22(11):1379-1385.

13. Essien EJ, Mgbere O, Monjok E, Ekong E, Abughosh SM, Holstad MM. Predictors of frequency of condom use and attitudes among sexually active female military personnel in Nigeria. HIV/AIDS Research and Palliative Care 2010:2 77-88.

\section{Figures}

\section{Knowledge of HIV Transmission and Prevention}

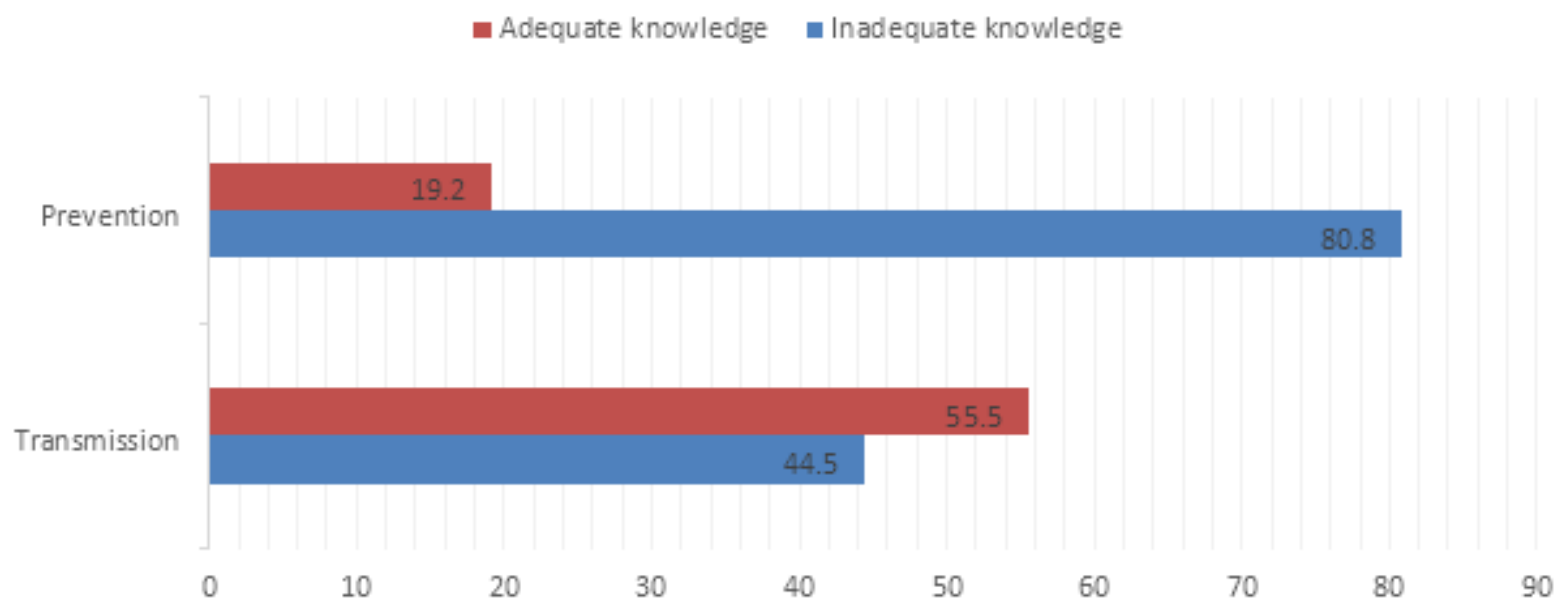

\section{Figure 1}

Knowledge categories for HIV transmission and prevention 


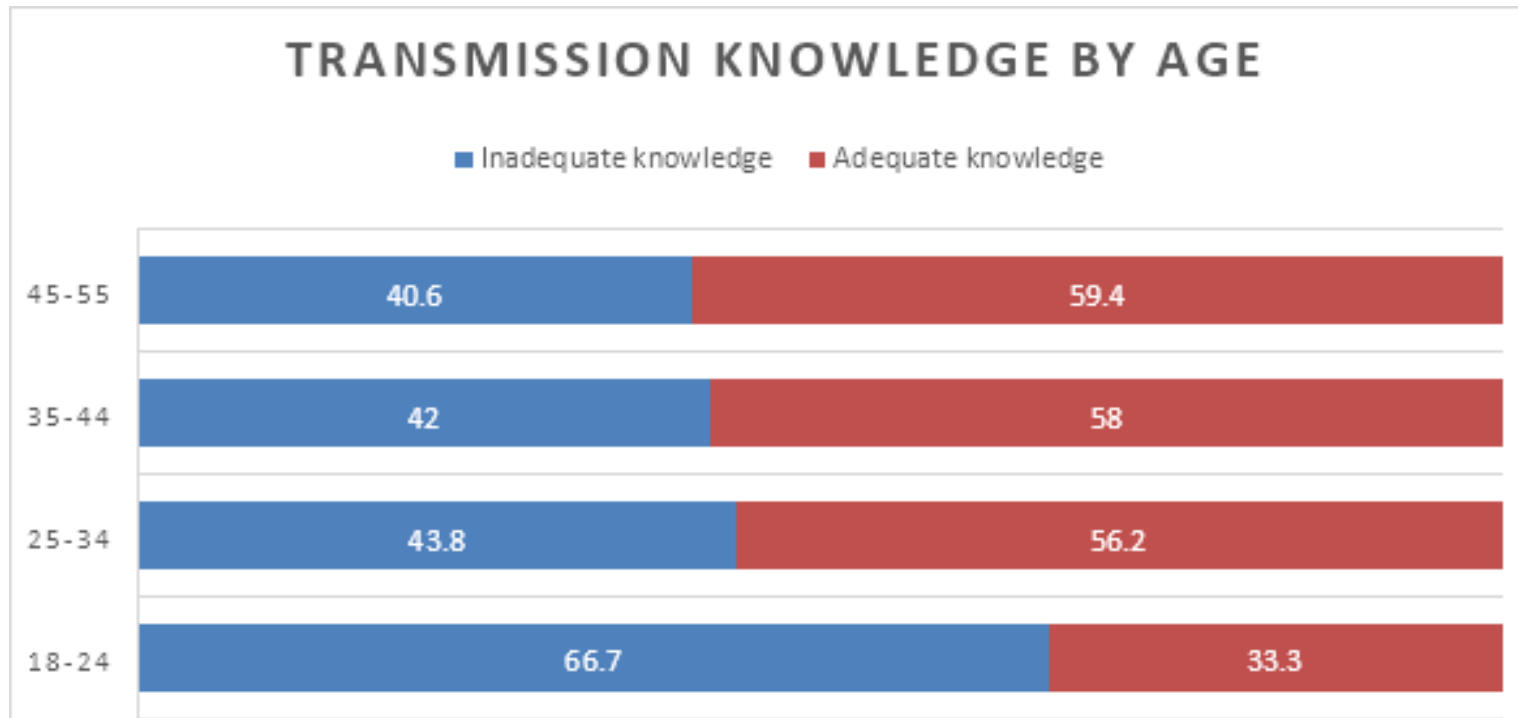

Figure 2

Knowledge of HIV transmission by age groups 